\title{
Traditions médicales et développement sanitaire
}

Laurent Pordié (éd.), Panser le monde, penser les médecines. Traditions médicales et développement sanitaire, Paris, Karthala, 2005, 326 p.

Frédéric Bourdier

\section{(2) OpenEdition}

12 Journals

Édition électronique

URL : http://journals.openedition.org/transcontinentales/1469

DOI : 10.4000/transcontinentales. 1469

ISBN : 978-2-8218-1408-0

ISSN : $1775-397 X$

\section{Éditeur}

Editions de la maison des sciences de l'homme

\section{Édition imprimée}

Date de publication : 30 juin 2006

Pagination : 181-182

ISBN : 2200-92169-1

ISSN : 1950-1684

\section{Référence électronique}

Frédéric Bourdier, «Traditions médicales et développement sanitaire », Transcontinentales [En ligne], 2 2006, document 16, mis en ligne le 15 décembre 2012, consulté le 25 septembre 2020. URL : http:// journals.openedition.org/transcontinentales/1469; DOI : https://doi.org/10.4000/transcontinentales. 1469

Ce document a été généré automatiquement le 25 septembre 2020

Tous droits réservés 


\section{Traditions médicales et développement sanitaire}

Laurent Pordié (éd.), Panser le monde, penser les médecines. Traditions médicales et développement sanitaire, Paris, Karthala, 2005, 326 p.

\section{Frédéric Bourdier}

\section{RÉFÉRENCE}

LAURENT Pordié (ÉD.)

Panser le monde, penser les médecines. Traditions médicales et développement sanitaire, Paris, Karthala, 2005, 326 p.

1 Cet ouvrage collectif invite à suivre les cheminements sociaux qui accompagnent des projets sanitaires dans des contextes sociogéographiques variés. L'intention est de se pencher sur les interférences entre savoirs vernaculaires, projets de santé publique et logiques de développement international.

Une première démarche adoptée consiste à connaître l'environnement social et culturel d'un système sanitaire. Un autre propos vise à retranscrire une intervention spécifique en fonction des dynamiques sociopolitiques et économiques villageoises. Les deux approches suivantes se situent dans le champ de l'évaluation anthropologique : analyse sociale des interventions provenant de l'extérieur et appréciation de leurs implications tant au niveau de la société qu'au niveau de la santé elle-même. La portée du livre est ambitieuse par le champ d'investigation qu'elle entend recouvrir, ainsi que par les procédures d'analyse utilisées oscillant entre des considérations générales et des analyses localement ciblées. Tel est l'objectif clairement établi. Le défi revient justement à articuler les premières réflexions comme celles de Guerci et Singleton qui se situent un peu trop en état de lévitation avec des pratiques sociales que la plupart des autres auteurs s'attachent à ancrer dans des processus de développement ciblés.

Parallèlement des contributions comme celles de Deliège et Diop survolent les comportements de santé en se concentrant arbitrairement sur un aspect, comme la 
pauvreté, ou en l'intégrant systématiquement à l'ensemble des phénomènes et représentations susceptibles de circonscrire les logiques populaires. À trop envisager un effet de cause à effet ou inversement à essayer d'articuler le tout dans le tout sans effort de pondération, il devient ardu de dégager les tendances sociales et culturelles dont on ne peut pourtant nier l'existence, d'autant plus qu'elles constituent le fondement anthropologique initial du présent livre.

D'autres contributions, plus constructives car elles restituent un contexte avant d'entrevoir les modalités de changement survenant en temps d'intervention sanitaire, présentent le développement comme un processus inachevé, en cours de négociation, entouré de contradictions. Hancart Petitet, Sujatha puis Bordes montrent que des transformations délibérées du système de santé génèrent de nouvelles formes de configurations sociales qui reconditionnent à leur tour les pratiques de santé.

Si l'ouvrage mentionne le vocable "tradition", un de ses multiples apports est de la présenter sous une forme innovante, dynamique, sans cesse remise en question. Ce qu'il convient d'appeler les traditions médicales constitue un enjeu pour les acteurs de développement ainsi que le démontre Laplante quand elle évoque comment des savoirs thérapeutiques en Amazonie génèrent une forme de sous-développement lorsque les connaissances vernaculaires sont déniées ou passées sous silence. Au demeurant, vu ce qu'ils représentent, dans l'imaginaire comme dans la réalité, lesdits processus de transformation des savoirs constituent une source de profit allant grandissant. D'autres auteurs montrent que des savoirs autochtones quittent leur habitat culturel et se meuvent dans un langage scientifique destiné à prouver leur légitimité, notamment en vue d'une évaluation clinique. À l'heure de la globalisation, la notion de marché de l'évaluation thérapeutique occupe indéniablement une portée heuristique dont Pordié présente une analyse systémique pouvant servir de modèle. Une étude de cas du marché clinique de la «tradition» aurait néanmoins permis de souligner les chevauchements complexes qui en découlent dans un contexte précis.

Le livre d'une grande rigueur apporte finalement une perspective soucieuse de mettre à jour les liens entre pratiques vernaculaires et enjeux de développement, sans pour autant tomber dans le piège de la finalité. À le lire, on découvre de nouvelles pistes d'investigations qui feront référence pour de futurs ouvrages.

\section{AUTEURS}

\section{FRÉDÉRIC BOURDIER}

Institut de recherche pour le développement (IRD) 